\title{
THE PRESENT METHODS OF PASTURE ESTABLISHMENT
}

\author{
C. J. BAKER \\ Senior Lecturer in Farm Mechanization, Massey University, \\ Palmerston N orth
}

Cultivation and the placement of seed in a suitable environment in which to germinate and establish is as much an art as it is a science. While the components of such a seedbed can be modified scientifically, their identification and the selection of the most suitable sowing technique in a field situation are seldom aided by objective measurements. The choice of which technique to implement in any one situation requires judgement acquired mainly from experience.

\section{SEEDBED PREPARATION}

While the cultivation techniques preceding sowing will have a major influence on the establishment of a pasture sward, the final degree of success is a function of the method of seed placement as well as the condition of the seedbed. Detailed consideration of tillage and seedbed preparation, however, is beyond the scope of this paper.

\section{SEED SOWING}

In dry soils especially, few of the commonly listed functions of a seed sowing machine will outweigh its obligation to form a consolidated furrow in which the seed is placed at uniform depth and spacing (Duffee, 1940) and in close proximity to the fertilizer. The V-ring roller drill has given consistently good results in this respect for a number of years (Cross, 1959). The wedging action of the rings provides consolidation at the base of the groove and encourages upward capillary movement of water from the subsoil. Seed and fertilizer broadcast simultaneously behind the rollers accumulate at the bottom of the grooves and a light harrowing covers the seed with loose soil dislodged from the apexes of the adjacent ridges.

In support of the importance of consolidation beneath the seed, recent trials at Massey University (involving four different levels of V-ring roller consolidation at, and prior to sowing) pro- 
TABLE 1: EFFECT OF METHOD OF SOWING ON ESTABLISHMENT AND YIELD OF RYEGRASS AND CLOVER

\begin{tabular}{|c|c|c|c|c|}
\hline & \multicolumn{2}{|c|}{$\begin{array}{c}15 \mathrm{lb} \text { Seeding Rate/ac } \\
\text { Plants/sq. ft } \quad \text { !b D.M. Yield/ac }\end{array}$} & \multicolumn{2}{|c|}{$\begin{array}{c}30 \mathrm{lb} \text { Seeding Rate/ac } \\
\text { Plants/sq. ft } \quad \mathrm{lb} \text { D.M. Yield /ac }\end{array}$} \\
\hline SpRING Sown & (14 days) & (40 days) & (14 days) & (40 days) \\
\hline Broadcast & 72 & 229 & 98 & 271 \\
\hline V-ring roller drill & 120 & 549 & 177 & 695 \\
\hline Grain drill $31 / 2$ in rows . . & a3 & 759 & - & - \\
\hline AUtumn Sown & (14 days) & (71 days) & (14 days) & (71 days) \\
\hline $\begin{array}{l}\text { Broadcast } \ldots \\
\text { V-ring roller drill } \\
\text { Grain drill } 31 \frac{1}{2} \text { in rows } \ldots\end{array}$ & $\begin{array}{l}44 \\
93 \\
93\end{array}$ & $\begin{array}{l}406 \\
511 \\
692\end{array}$ & $\begin{array}{r}79 \\
151 \\
151\end{array}$ & $\begin{array}{r}494 \\
1,033 \\
1,089\end{array}$ \\
\hline
\end{tabular}


duced significantly greater yields of timothy and perennial ryegrass in the tractor wheel marks on top of the rolling than in any of the rolled treatments themselves.

Modified Cambridge rollers have also found a diversified use with seedboxes, but suffer slightly through insufficient precision in directing the broadcast seed and fertilizer to the bottom of the more shouldered grooves.

Split coulter attachments for some hoe coulter drills allow the 3 to $31 / 2$ in. row spacing common with roller drills, but with less precise placement. Nevertheless, where moisture has not been limiting, establishment by such machines has given worthwhile results in the past and has the advantage that the attachments are a small capital item in addition to a grain drill.

It appears that any notable movement towards the use of more concentrated fertilizers will need to be accompanied by the provision of machines capable of separate placement of this fertilizer up to 2 in. from (usually below) the seed. Intimate contact between the two can induce loss of germination from salt effects, especially in dry soils (Carter, 1967).

The broadcasting of seed on to seedbeds not pressed to shape by a V-ring roller usually falls far short of precision placement, depth control and fertilizer location. Subsequent harrowing or rolling does little to alleviate this inadequacy and heavier seed rates seldom offset the initial deficiencies (Table 1, from Cross, 1959, and M. W. Cross, unpublished data). These results indicate that even the heavy rate $(30 \mathrm{lb} / \mathrm{ac})$ broadcast failed to produce as much as either of the precisely sown light rates $(15 \mathrm{lb} /$ ac) in either spring or autumn sowing. In addition, the technique is open to the problems arising from inherent variations between machines commonly used for broadcasting in wide bouts.

Other factors, of course, may preclude the use of one or another type of semi-precision implement. Damp soil at the time of sowing will often adhere to the rings of rollers, while wind, slope, bumps, stones and humidity can influence distribution from broadcast seeders and roller drills alike. Depth of sowing of pasture seeds varies with the species, but is normally considerably shallower than for most other crops. Arndt (1965), in simulated conditions, found that depths of sowing in the ratio of $1: 2: 3$ created a mechanical impedance at all levels of moisture content in the ratio $1: 1.75: 2.50$. Thus, seeds set at $1 \frac{1}{2}$ in. depth were faced with $21 / 2$ times as much resistance as those set at $1 / 2$ in. From these results, he suggested that serious consideration 
should be given to shallow planting as a means of escape from mechanical impedance problems where they existed.

A number of other factors may override the methods and machinery used in seedbed preparation and sowing. Amongst these, few will have more pronounced effects than the species of seeds sown and the relative proportions of one to another in a mix (Brougham, 1954a, c, d) . Brougham (1954b) also demonstrated the importance of management in the early stages of growth in relation to establishment, but further consideration of these aspects is beyond the scope of this paper.

\section{SURFACE SEEDING}

The introduction of suitable herbicides, the uncertainty of world animal produce markets, and the appearance of improved machines have all led to a recent rekindling of interest in methods of seeding directly into, and on to undisturbed seedbeds. The various practices have as their aims:

(1) Complete renewal of the vegetative cover - e.g., establishment of pasture from fed-off crop stubble, a cereal crop from pasture, or any crop or pasture from virgin land.

(2) Changing the botanical balance of a pasture sward. This normally involves the introduction of a species more suited to a particular part of the growing season, or to animal performances.

Amongst the advantages of surface seeding into turf is the type of seedbed many of these physically undisturbed soils offer. For example, structure, consolidation and smoothing are very often nearly ideal, while ground moisture supply as a function of consolidation can be expected to be at a maximum also. Fertility is subject to local conditions and is easily modified, while aeration can be marginal or even inadequate, depending on the history of the existing sward and the drainage characteristics of the underlying soil.

\section{DRILLING MACHINERY}

It has become increasingly apparent that one of the major and most influential variables in such establishment techniques is the method and machinery used in drilling the seed. Machinery development, to date, has enabled successful application of this technique to be undertaken, but the collection of fundamental de- 
sign data has been notably lagging behind the wealth of relevant chemical and agronomic information collected in a relatively short time. Research so far has yielded few quantitative data on which to make categorical statements concerning the place and likely success of the various techniques available (Charles, 1962; B. Dangol, unpublished data). Recent work in New Zealand and elsewhere shows hope of collecting some of the much needed fundamental data.

It is important to recognize that all surface seeding techniques are "short-cut" by design and are therefore less tolerant of suboptimal techniques and conditions than is the case with conventional seedbed preparation and sowing. In this respect, it is unfortunate that favourable climatic conditions at the time of drilling in many areas of New Zealand have produced flatteringly good results from some otherwise poor techniques of establishment. Only when the weather is not kind are the flaws of these techniques demonstrated; and, even then, failure of a crop is often put down to other factors,

It is necessary to make the distinction between requirements of techniques with and without the aid of a chemical herbicide. The latter practices normally fall into the category of oversowing or overdrilling.

\section{OVERSOWING}

Oversowing (surface broadcasting of seed) is to be discouraged except where passage of land vehicles is impossible or not economically feasible. Promising results with inoculated clovers were reported by During et al. (1963) on stony yellow-brown loams near Te Anau, and pre- and post-seeding surface disturbance by harrows, discs or stock will normally assist in establishing the desirable species, but it can seldom be considered a precision placement technique. Cross. and Glenday ( 1956) demonstrated this with short-rotation ryegrass (Table 2).

TABLE 2: EFFECT OF SEED PLACEMENT IN AN UNDISTURBED SEEDBED

\begin{tabular}{|c|c|c|c|c|c|}
\hline & & & \multicolumn{3}{|c|}{$\begin{array}{c}\text { Number of Established } \\
H_{1} \text { Plants } / \text { sq. yd }\end{array}$} \\
\hline $\begin{array}{l}\text { Broadcast } \quad . . \\
\text { Overdrilling: }\end{array}$ & $\mathrm{m}$ & י & "m & 6 & 36 \\
\hline Hoe coulters, 7 in. rows & $\ldots$ & & $\ldots$ & 221 & 228 \\
\hline Disc coulters, 7 in. rows & $\ldots$ & $\ldots$ & $\ldots$ & 186 & 207 \\
\hline
\end{tabular}




\section{OVERDRILLING}

The requirements for successful overdrilling in New Zealand were listed by M. W. Cross (unpublished data) .

(1) The drilling machine should leave a plant-free track, $1 \%$ in. to 2 in. wide and of uniform shallow depth through all types of vegetative cover and soil conditions.

(2) It should open the furrow continuously from one end of the field to the other with individually mounted coulters.

(3) It should distribute seed and fertilizer uniformly along the furrow at the required rates and deal with a wide range of seeds.

(4) Loose or standing surface vegetation and roots or stones should not cause blockages or damage.

(5) If possible, the seed should be covered with soil and the machine should have a reasonably high working speed.

In addition, he stressed the need for hard grazing or mowing prior to drilling and the desirability of performing the operation in autumn rather than spring to reduce competition further (especially from clovers) and ensure an adequate moisture supply to the surface soil layers. Time of sowing in difficult yellowbrown loams was shown by Cullen (1965) to be also of great importance when oversowing.

The seed is covered by the use of light harrows or individual chains (or similar devices) behind each drill coulter.

\section{DIRECT DRILLING}

When herbicides are used in conjunction with the drill, they largely replace the latter's mechanical obligation to remove competition, and thereby alter the shape of the seed groove required. Competition for most nutrients and moisture from the suppressed or desiccated plants in the vicinity of the introduced species is eliminated. Light may still be restricted, at least until the new shoots emerge through the dead canopy, and it is possible that decomposition of this vegetation may temporarily reduce levels of available soil nitrogen to the detriment of the introduced species (L. W. Blackmore, pers. comm.) .

It appears that the introduced seed requires only a relatively narrow vertical slot in which to germinate. However, it is not yet clear what the specific physical requirements of this slot are. 
The extent of localized consolidation, shape and degree of cracking, and loose soil generation have been suggested by Baker (1969) as factors likely to influence root development in this environment, while the extent of closure and shape of the slit, and the presence of a soil flap, may well be the controlling factors in shoot emergence. It is further suggested that the drill and soil features which themselves may govern the above could be: tine shape and pitch, disc type (flat or concave), disc angle (to the horizontal), tilt angle (to the perpendicular), relationship of two or more coulters or types to each other (for any one coulter assembly), speed of travel, soil moisture content, mode of depth and pitch control and trailing arm geometry, soil type, vegetative cover, and time interval between spraying and drilling, Such factors as seed variety, fertility, fertilizer placement and climate will, of course, have major influences as well. All other above listed requirements for overdrilling machines and techniques still apply to these chemically assisted direct drilling practices.

\section{BROADCASTING SEED}

Broadcasting seed. on to chemically treated seedbeds has much to recommend it in comparison with oversowing from the viewpoint of competition, but both are still likely to fall well short of the ideal, or of techniques involving drilling.

\section{FED-OFF CROPS}

The establishment of pasture by surface seeding, following a fed-off crop such as choumoellier or maize, highlights the need for attention to surface smoothing during the preparation of the initial seedbed. Drilling requirements fall somewhere between those for overdrilling and direct drilling, depending on the abundance of regenerated weeds and the economics of chemical weed control. Crop trash can present problems with drill operation. In these circumstances, the use of disc type drills is to be recommended. Where the technique is required to approach that of overdrilling (because of surface weeds) a dished disc travelling with a slight $\left(5^{\circ}\right)$ negative tilt and approximately $15^{\circ}$ disc angle has given consistently good results, while an arrangement of two flat discs at $10^{\circ}$ included angle to each other at their bases and preceded by a third independent vertical flat disc was claimed by Taylor (1969) to be desirable in trashy, but competition-free situations. 
Until the requirements of seedling establishment in physically "undisturbed" seedbeds is better documented, the choice of machinery to implement the various techniques will remain somewhat arbitrary.

\section{REFERENCES}

Arndt, W., 1965: Aust. J. Soil Res., 3-4: 55-69.

Baker, C. J., 1969: Proc. 1st Massey Fm. Mach. Engng Sem. (in press).

Brougham, R. W., 1954a: N.Z.Jl Sci. Technol., 35A: 518-38.

1954b: N.Z. Jl Sci. Technol., 35A: 539-49.

1954c: N.Z. Il Sci. Technol., 36A: 47-59.

1954d: N.Z. Il Sci. Technol., 36A. 365-74.

Carter, 0. G., 1967: Ausi. J.exp. Agric. Anim. Husb., 7: 174-80

Charles, A. H., 1962: Herb. Abstr., 32: 175-81.

Cross, M. W., 1959: Sheep/mg A.: 107-16.

Cross, M. W.; Glenday, A., 1956: N.Z. Il Sci. Technol., 38A: 416-30.

Cullen, N. A., 1965: N.Z. Jlagric. Res., 9: 363-74.

Duffee, F. W., 1940: Agric. Engrig, 21: 21.

During, C.; Cullen, N. A.; Mountier, N. S., 1963: N.Z. Il agric. Res., 6: 416-31.

Taylor, R., 1969: Proc. 1st Massey Fm. Mach. Engng Sem. (in press).

\section{DISCUSSION}

To a suggestion that seed-coating would be beneficial, Baker said that with all the factors involved he felt that perhaps seed-coating would be beneficial used in conjunction with, rather than instead of, better seedbed preparations. Treating seed may 'mean to give it ability to germinate at a depth of $2 \mathrm{in}$. instead of $1 / 2 \mathrm{in}$. or in loose rather than in wellconsolidated soil.

Certainly, in marginal conditions, the best of preparation and consolidation was needed but he felt that good consolidation was beneficial in all circumstances. 